\title{
Quality of Two Florida Blueberry Cultivars after Packaging and Storage
}

\author{
W.R. Miller and R.E. McDonald \\ U.S. Department of Agriculture, Agricultural Research Service, U.S. \\ Horticultural Research Laboratory, 2120 Camden Road, Orlando, FL 32803
}

\author{
T.E. Cracker \\ Fruit Crops Department, University of Florida, Gainesville, FL 32611
}

Additional index words. Vaccinium corymbosum, V. ashei, highbush blueberry, rabbiteye blueberry, postharvest

\begin{abstract}
Blueberry cultivars Sharpblue (mainly Vaccinium corymbosum L.) and Climax $(V$. ashei $L$.) were band-harvested on three occasions and manually packaged into 0.275 liter fiber-pulp cups or automatically packaged in vented polystyrene cups. Berries were evaluated after 1,2, or 3 weeks of storage at $1 \mathrm{C}$ and after 2 additional days of storage at 16C, a time frame that simulated a merchandising period. Weight loss of fruit packaged in polystyrene cups was $<1 \%$ during 3 weeks of storage at IC, whereas weight loss of berries packaged in fiber-pulp cups was $\approx 5.0 \%$ after similar storage. 'Sharpblue' berries were softer at harvest and after each storage duration than 'Climax' berries. Decay increased to $\approx 7 \%$ for 'Climax' and $28 \%$ for 'Sharpblue' after 3 weeks of storage at $1 \mathrm{C}$. Package type did not affect decay incidence after 3 weeks of storage; but after 2 additional days at $16 \mathrm{C}$, decay incidence was slightly higher for berries packaged in polystyrene compared with those packaged in fiber-pulp cups. 'Sharpblue' should be packaged only in fiber-pulp cups and marketed quickly after harvest to avoid excessive decay.
\end{abstract}

Florida blueberry hectarage increased from $<40.5$ ha in 1973 to 429 ha in 1985 (Crocker and Lyrene, 1985) and 853 ha in 1989 (Crocker and Willis, 1989). Due to climate and the use of low-chill cultivars, Florida has an early blueberry season compared with other states. Continued growth of this industry in Florida depends on the introduction of early maturing cultivars to extend the state's production season. 'Sharpblue', a highbush cultivar, was one of the first hybrids specifically developed for Florida's soil and climatic conditions. It is still the leading early producer, accounting for $>80 \%$ of early blueberries in Florida (Lyrene and Sherman, 1988). Comprehensive postharvest information on 'Sharpblue' is lacking because early plantings were made mostly by homeowners for noncommercial use, and only in recent years has 'Sharpblue' become an important commercial cultivar.

In this study, various postharvest quality characteristics of 'Sharpblue' fruit were compared with those of 'Climax' fruit. 'Climax' is a well-established rabbiteye cultivar that produces high-quality fruit that exhibit

\footnotetext{
Received for publication 20 Dec. 1991. Accepted for publication 17 Aug. 1992. We acknowledge the contributions of Victor Chew, statistician, U.S. Dept. of Agriculture (USDA), Gainesville, Fla., and the technical support of Cathy Carroll, USDA, Orlando, Fla., during this study. Mention of a trademark, warranty, proprietary product, or vendor does not constitute a guarantee by the USDA and does not imply its approval to the exclusion of other products or vendors that may also be suitable. The cost of publishing this paper was defrayed in part by the payment of page charges. Under postal regulations, this paper therefore must be hereby marked advertisement solely to indicate this fact.
}

good shelf life during marketing (Miller and Smittle, 1987). Since 'Sharpblue' matures early and there is little competition from other blueberry cultivars, it commands a high revenue per unit in the marketplace. Therefore, growers have an incentive to ship it to distant markets that are willing to pay higher prices.

Harvest dates of 'Sharpblue' and 'Climax' do not overlap, and factors such as weather at harvest time and cultural and handling methods influence postharvest fruit quality. Growers need improved postharvest information on highly perishable commodities such as blueberries, which are mostly exported via air cargo under less than optimum environmental conditions.

The purpose of this study was to compare postharvest quality characteristics of 'Climax' and 'Sharpblue' berries packaged manually in fiber-pulp cups or automatically in polystyrene cups. Comparisons were made after extended periods of simulated commercial storage and subsequent merchandising conditions.

All berries were harvested from a large plantation in Alachua County in north-central Florida. 'Sharpblue' fruit were harvested three times at 7-day intervals starting 17 Apr. 1990, whereas 'Climax' were harvested once on 18 May 1990. All berries were hand-harvested into plastic pails (3.8 liters) which, when filled, were dumped into plastic field bins (18.3 liters). Filled bins were transported from the field to the packinghouse for grading and packaging. Immediately after harvest, half of the berries was commercially packed by hand in 0.275 liter fiber-pulp cups with a cellophane cap retained by a rubber band. The remaining half was packaged by machine into polystyrene cups of similar size, formed from flat polystyrene stock just before filling, and covered with Mylar film (100 gauge, $27 \mu \mathrm{m}$ thick), each cover with nine 2-mm ventilation holes. Covers were automatically heat-sealed in place at the top perimeter surface of the cup. Twelve tilled cups of berries were placed into each shipping tray and transported to the Orlando laboratory by air-conditioned automobile (about 2-h travel time).

On arrival, the berries were weighed, and the cups of berries were randomized into eight storage lots. For each test (replication), storage lots consisted of three cups of fruit for each cultivar/package type combination. The storage regimes were 1) initial (overnight at $1 \mathrm{C}$ ); 2) initial plus 2 days at $16 \mathrm{C}[90 \%$ relative humidity (RH)]; 3) 7 days at $1 \mathrm{C}(90 \% \mathrm{RH})$; 4) 7 days at $1 \mathrm{C}$ plus 2 days at $16 \mathrm{C}$; 5) 14 days at $1 \mathrm{C}$; 6) 14 days at $1 \mathrm{C}$ plus 2 days at $16 \mathrm{C}$; 7) 21 days at $1 \mathrm{C}$; and 8) 21 days at $1 \mathrm{C}$ plus 2 days at $16 \mathrm{C}$.

After each storage period, air samples were drawn by syringe from the head space in the polystyrene cups and analyzed by gas-liquid chromatography (model 5880; Hewlett Packard, Avondale, Pa.) for concentrations of $\mathrm{O}_{2}$ and $\mathrm{CO}_{2}$. Berry weights for each cup were recorded and fruit were removed from the packages. Each berry was inspected and rated according to firmness, juice leakage, decay, and whether the berry was mummified, not mature-blue, or damaged by handling (cull). Berries were subjectively rated firm or soft, according to the degree of berry yield to lightly applied finger pressure. Decay was rated according to the presence of mold or juice leaking at the stem scar or whether the berries were extremely mushy. The percentage of fruit in each condition category was determined on a fresh-weight basis. All berries were salable except culls and those with decay.

A 150-g sample of fruit (soft and firm) was obtained (50 g from each of three cups) from each treatment lot after inspection and frozen for later measurements of soluble solids concentration (refractometer), $\mathrm{pH}$, and acidity (Smittle and Miller, 1988). Remaining berries were placed on plates for a seven-member taste panel to evaluate flavor and texture based on a hedonic scale ranging from 0 to 100 , nonacceptable to excellent.

For each inspection, analyses of variance procedures were used to analyze the data as a split-plot experiment, with cultivars as the main plot and package types as the subplots. Differences among cultivars and among package types and their interactions were tested for statistical significance.

Eighty-six percent of 'Climax' berries was rated firm after overnight storage, and $56 \%$ was firm after 3 weeks of storage at $1 \mathrm{C}$. The percentage of soft fruit increased from $12 \%$ to $38 \%$ during this storage time (Table 1). Decay developed on $5 \%$ of 'Climax' berries after 3 weeks of storage at $1 \mathrm{C}$, and increased to $12 \%$ after 2 additional days of storage at 16C. Culls represented $1 \%$ to $2 \%$ of fruit weight, and the percentage was not affected by cultivar or storage duration.

The percentage of 'Sharpblue' berries rated firm remained relatively constant (except after the final storage period), ranging from $43 \%$ to 
$48 \%$ during 3 weeks of storage at $1 \mathrm{C}$, and from $31 \%$ to $48 \%$ after 2 additional days of storage at $16 \mathrm{C}$ (Table 1). The percentage of firm berries was not affected by cultivar $(P<0.05)$ after 1 and 2 weeks of storage at $1 \mathrm{C}$ or $1 \mathrm{C}+2$ days of storage at $16 \mathrm{C}$, or after 3 weeks of storage at $1 \mathrm{C}+2$ days of storage at $16 \mathrm{C}$.
During storage, as the percentage of decay in 'Sharpblue' berries increased, the percentage of firm fruit remained relatively constant, but the percentage of soft fruit decreased. For 'Sharpblue', after 1,2, or 3 weeks of storage at $1 \mathrm{C}$ plus 2 additional days at $16 \mathrm{C}$, berry decay increased to $18 \%, 32 \%$, and $48 \%$, respec- tively. Decay increased faster at $16 \mathrm{C}$ than at $1 \mathrm{C}$ storage for both cultivars, and there was significantly more decay in 'Sharpblue' fruit than in 'Climax' fruit (Table 1). After 3 weeks at $1 \mathrm{C}, 94 \%$ and $69 \%$ of fruit were rated sound [(firm plus soft) - (decayed + leakers + culls)] for 'Climax' and 'Sharpblue', respectively,

Table 1. Percent weight loss and percentage of blueberries rated firm, soft, or decayed by cultivar (CV) and package (PK) type according to storage duration and temperature regime.

\begin{tabular}{|c|c|c|c|c|c|c|c|c|c|}
\hline \multirow[b]{2}{*}{$\begin{array}{l}C V \text { and } \\
\text { PK type } \\
\end{array}$} & \multirow[b]{2}{*}{$\mathrm{df}$} & \multicolumn{4}{|c|}{ Percent } & \multicolumn{4}{|c|}{ Percent } \\
\hline & & $\begin{array}{r}\text { Wt } \\
\text { loss }\end{array}$ & Firm & Soft & Decayed & $\begin{array}{l}\mathrm{Wt} \\
\text { loss }\end{array}$ & Firm & Soft & Decayed \\
\hline & & \multicolumn{4}{|c|}{ Overnight at $I C$} & \multicolumn{4}{|c|}{ Overnight at $1 C+2$ days at $16 C$} \\
\hline $\begin{array}{r}\text { Climax } \\
\text { Poly }^{z}\end{array}$ & & & & & & & & & \\
\hline Pulp & & 0.9 & $\begin{array}{l}85.3 \\
87.4\end{array}$ & $\begin{array}{l}11.7 \\
11.2\end{array}$ & 1.1 & 0.3 & 84.2 & 11.6 & 2.1 \\
\hline Avg & & 0.5 & $\begin{array}{l}87.4 \\
86.4\end{array}$ & $\begin{array}{l}11.2 \\
11.5\end{array}$ & 0.5 & 1.7 & 89.7 & 9.0 & 0.6 \\
\hline \multicolumn{8}{|l|}{ Sharpblue } & 10.3 & 1.4 \\
\hline Poly & & 0.3 & 46.9 & 44.6 & 7.1 & 0.5 & 47.2 & 40.3 & 11.3 \\
\hline Pulp & & 1.0 & 42.3 & 48.5 & 7.4 & 3.2 & 43.2 & 43.7 & 11.3 \\
\hline Avg & & 0.6 & 44.6 & 46.6 & 7.3 & 1.8 & 45.2 & 42.0 & 11.3 \\
\hline \multicolumn{10}{|l|}{ ANOVA } \\
\hline $\mathrm{CV}$ & 1 & $0.03^{\mathrm{Ns}}$ & $15323^{*}$ & $10779^{*}$ & $367^{*}$ & $6.0^{*}$ & $15724^{*}$ & $9037 *$ & $887^{*}$ \\
\hline PK & 1 & $4.2^{*}$ & $0.2^{\mathrm{Ns}}$ & $4.4^{\mathrm{Ns}}$ & $1.2^{\mathrm{Ns}}$ & $38.1^{*}$ & $5.6^{\mathrm{ss}}$ & $1.1^{\mathrm{Ns}}$ & $5.5^{\mathrm{Ns}}$ \\
\hline $\mathrm{CV} \times \mathrm{PK}$ & 1 & $0.03^{\mathrm{Ns}}$ & $113^{\mathrm{Ns}}$ & $65^{\mathrm{ss}}$ & $0.7^{\mathrm{vs}}$ & $4.0^{*}$ & $205^{\mathrm{Ns}}$ & $84^{\mathrm{Ns}}$ & $5.3^{\mathrm{Ns}}$ \\
\hline Error ${ }^{x}$ & 4 & 0.06 & 672 & 477 & 19.2 & 0.5 & 313 & 131 & 61.8 \\
\hline Climax & & \multicolumn{4}{|c|}{1 wk at $l C$} & \multicolumn{4}{|c|}{1 wk at $1 C+2$ days at $16 C$} \\
\hline Poly & & 0.4 & 76.0 & 19.2 & 1.7 & 0.6 & 86.3 & 9.7 & 2.1 \\
\hline Pulp & & 2.6 & 75.4 & 23.1 & 0.4 & 3.0 & 71.9 & 24.7 & 0.7 \\
\hline Avg & & 1.5 & 75.7 & 21.2 & 1.0 & 1.8 & 79.1 & 17.2 & 1.4 \\
\hline \multicolumn{10}{|l|}{ Sharpblue } \\
\hline Poly & & 0.4 & 44.7 & 43.2 & 10.6 & 0.8 & 55.1 & 25.3 & 17.8 \\
\hline Pulp & & 2.3 & 40.4 & 46.4 & 11.0 & 4.3 & 40.3 & 38.5 & 19.0 \\
\hline Avg & & 1.3 & 42.5 & 44.8 & 10.8 & 2.5 & 47.7 & 31.9 & 18.4 \\
\hline \multicolumn{10}{|l|}{ ANOVA } \\
\hline $\mathrm{CV}$ & 1 & $0.2^{*}$ & $9899 *$ & $4994 *$ & $863^{*}$ & $5.3^{*}$ & $8861 *$ & $1954^{\mathrm{Ns}}$ & $2609 *$ \\
\hline PK & 1 & $38.0^{*}$ & $54.8^{\mathrm{Ns}}$ & $114^{\mathrm{Ns}}$ & $2.2^{\mathrm{ss}}$ & $76.9^{*}$ & $1921^{*}$ & $1787^{*}$ & $0.05^{\mathrm{Ns}}$ \\
\hline $\mathrm{CV} \times \mathrm{PK}$ & 1 & $0.3^{N 3}$ & $29.6^{\mathrm{Ns}}$ & $1.1^{\mathrm{Ns}}$ & $6.4^{\mathrm{ss}}$ & $2.6^{*}$ & $0.4^{\mathrm{NS}}$ & $7.2^{\mathrm{Ns}}$ & $15.0^{\mathrm{Ns}}$ \\
\hline Error & 4 & 0.01 & 149 & 139 & 3.4 & 0.12 & 126 & 673 & 252 \\
\hline Climax & & \multicolumn{4}{|c|}{2 wk at $1 C$} & \multicolumn{4}{|c|}{2 wk at $I C+2$ days at $16 C$} \\
\hline Poly & & 0.8 & 72.3 & 23.5 & 1.7 & 0.9 & 72.8 & 13.7 & 12.9 \\
\hline Pulp & & 3.9 & 53.5 & 43.2 & 2.3 & 4.3 & 63.4 & 30.0 & 5.7 \\
\hline Avg & & 2.3 & 62.9 & 33.4 & 2.0 & 2.6 & 68.1 & 21.8 & 9.3 \\
\hline \multicolumn{10}{|l|}{ Sharpblue } \\
\hline Poly & & 0.1 . & 53.3 & 25.0 & 20.3 & 1.0 & 50.4 & 13.5 & 34.9 \\
\hline Pulp & & 4.2 & 41.8 & 36.0 & 19.5 & 6.7 & 46.4 & 23.9 & 28.9 \\
\hline Avg & & 2.1 & 47.5 & 30.5 & 19.9 & 3.8 & 48.4 & 18.7 & 31.9 \\
\hline \multicolumn{10}{|l|}{ ANOVA } \\
\hline $\mathrm{CV}$ & 1 & $0.3^{\mathrm{Ns}}$ & $2137^{\mathrm{Ns}}$ & $74.3^{\mathrm{Ns}}$ & $2879 *$ & $13.8^{*}$ & $3505^{\mathrm{Ns}}$ & $89.5^{\mathrm{Ns}}$ & $4572^{\text {Ns }}$ \\
\hline PK & 1 & $120^{*}$ & $2071^{*}$ & $2118^{*}$ & $1.0^{\mathrm{Ns}}$ & $188^{*}$ & $409^{*}$ & $1608^{*}$ & $394 *$ \\
\hline $\mathrm{CV} \times \mathrm{PK}$ & 1 & $2.6^{\mathrm{Ns}}$ & $122^{\mathrm{NS}}$ & $168^{*}$ & $4.9^{\mathrm{Ns}}$ & $12.1^{*}$ & $64.2^{*}$ & $82.6^{\mathrm{NS}}$ & $3.6^{\mathrm{ks}}$ \\
\hline Error & 4 & 1.2 & 563 & 401 & 314 & 1.7 & 1035 & 274 & 837 \\
\hline Climax & & \multicolumn{4}{|c|}{3 wk at $1 C$} & & 3 wk at 1 & days at 16 & \\
\hline Poly & & 0.9 & 74.0 & 19.0 & 5.4 & 0.8 & 71.5 & 12.8 & 15.1 \\
\hline Pulp & & 5.3 & 37.7 & 56.2 & 5.5 & 6.4 & 50.3 & 40.6 & 8.3 \\
\hline Avg & & 3.1 & 55.9 & 37.6 & 5.4 & 3.6 & 60.9 & 26.7 & 11.7 \\
\hline Sharpblue & & & & & & & & & \\
\hline Poly & & 0.8 & 52.3 & 14.5 & 31.5 & 1.0 & 39.7 & 8.9 & 49.7 \\
\hline Pulp & & 6.1 & 41.4 & 30.5 & 25.2 & 7.4 & 23.1 & 28.6 & 46.7 \\
\hline Avg & & 3.5 & 46.8 & 22.5 & 28.4 & 4.2 & 31.4 & 18.1 & 48.2 \\
\hline ANOVA & & & & & & & & & \\
\hline $\mathrm{CV}$ & 1 & $1.3^{\mathrm{Ns}}$ & $739^{\mathrm{Ns}}$ & $2060^{\mathrm{Ns}}$ & $4740^{*}$ & $3.0^{\mathrm{Ns}}$ & $7842^{*}$ & $575^{\mathrm{Ns}}$ & $12006^{*}$ \\
\hline PK & 1 & $212^{*}$ & $5022^{*}$ & $6359^{*}$ & $87.0^{\text {ss }}$ & $320^{*}$ & $3196 *$ & $5086^{*}$ & $221^{\mathrm{Ns}}$ \\
\hline $\mathrm{CV} \times \mathrm{PK}$ & 1 & $1.9^{*}$ & $1453 *$ & $1019 *$ & $92.8^{\mathrm{Ns}}$ & $1.3^{\mathrm{Ns}}$ & $48.3^{\mathrm{Ns}}$ & $150^{\mathrm{Ns}}$ & $31.3^{\mathrm{Ns}}$ \\
\hline Error & 4 & 2.1 & 397 & 705 & 235 & 4.0 & 353 & 311 & 443 \\
\hline
\end{tabular}

yFiber-pulp package.

${ }^{x}$ Analysis of variance (ANOVA) mean square for harvest date (CV) used as error term.

s, "Nonsignificant or significant at $P \leq 0.05$, respectively, with associated mean square value. 
compared with $88 \%$ and $50 \%$ sound fruit after 2 additional days at $16 \mathrm{C}$.

All berries packaged in polystyrene cups were generally firmer than those in pulp cups after 1,2 , or 3 weeks of storage, regardless of the time/temperature regime. The difference in the percentage of firm berries by package type was significant $(P<0.05)$ after 2 or 3 weeks of storage, and the effect of storage on each cultivar depended on package type after storage for 3 weeks at 1C. Although berries stored for 2 or 3 weeks at 1C in fiber-pulp cups were significantly softer than those stored in polystyrene cups, package type generally did not affect the incidence of decay (except after 2 weeks of storage at $1 \mathrm{C}+2$ days at $16 \mathrm{C}$ ).

Berry weight loss averaged $3.3 \%$ after 3 weeks of storage at $\mathrm{IC}$, and weight loss generally was not affected by cultivar during 1C storage. Weight loss was significantly less for berries packaged in polystyrene cups than for

Table 2. Total soluble solids (TSS) concentration, acid, and flavor and texture index values for blueberries by cultivar (CV) and package (PK) type according to storage duration and temperature regime.

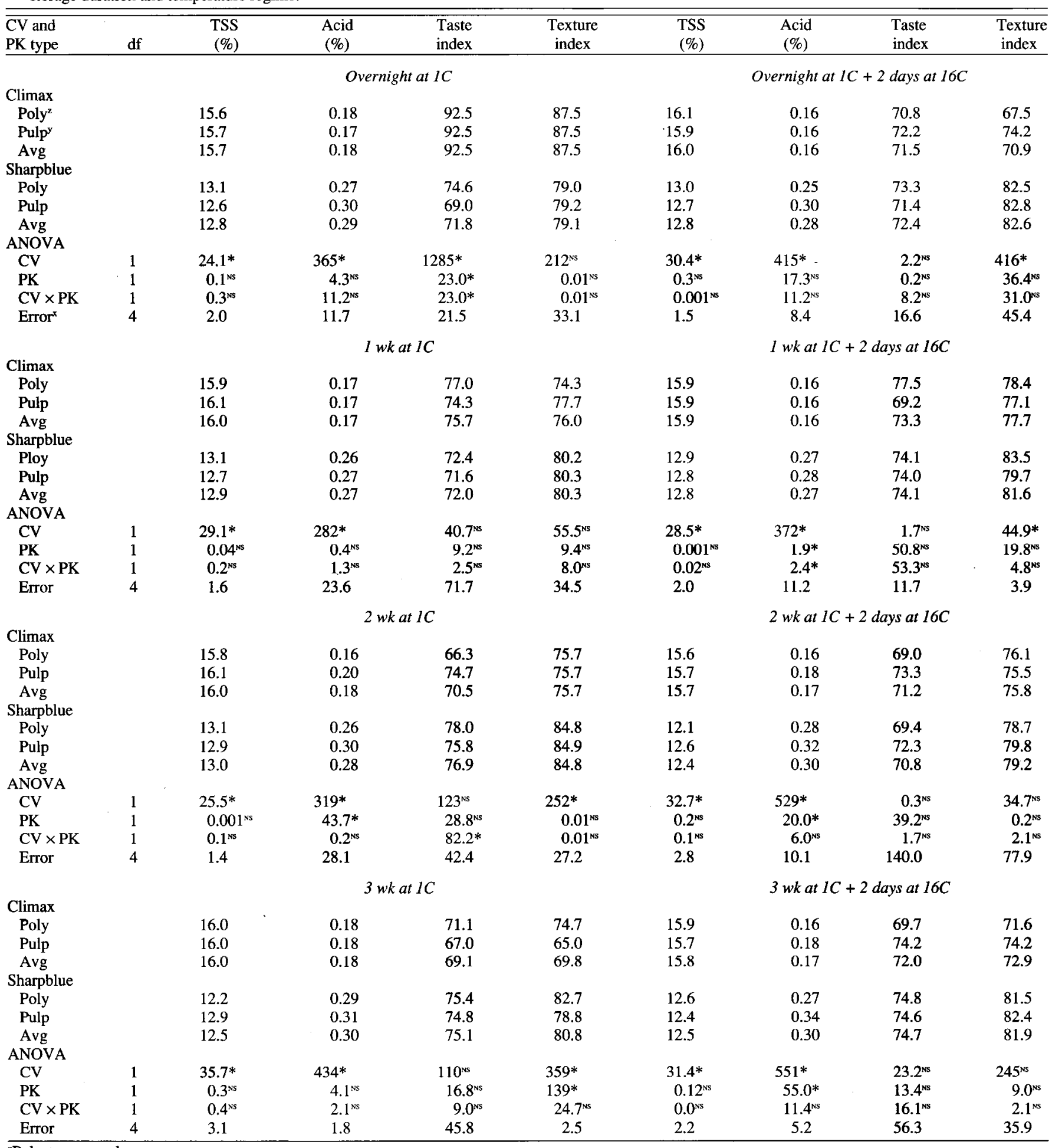

zPolystyrene package.

${ }^{y}$ Fiber-pulp package.

${ }^{x}$ Analysis of variance (ANOVA) mean square for harvest date (cultivar) used as error term.

ss, ${ }^{\star}$ Nonsignificant or significant at $P \leq 0.05$, respectively, with associated mean square value. 
those in pulp baskets after all storage regimes of 2 days at 16C (Table 1 ).

Berries packed in polystyrene cups lost $<1.0 \%$ in fresh weight during 3 weeks of storage at $1 \mathrm{C}$, where as berries packed in fiberpulp cups lost $\approx 1.6 \%$ fresh weight/week. During the additional 2 days of storage at $16 \mathrm{C}$, 'Sharpblue' fruit lost more $(P<0.05)$ weight than 'Climax' fruit, regardless of prior storage time, and the effect of cultivar on weight loss generally depended on package type.

Soluble solids concentration and titratable acidity differed $(P<0.05)$ by cultivar and averaged $16.0 \%$ and $0.18 \%$ for 'Climax' berries, and $12.5 \%$ and $0.29 \%$ for 'Sharpblue' berries, respectively, after the $1 \mathrm{C}$ storage regime; values were similar after 2 additional days of storage at $16 \mathrm{C}$ (Table 2). Acidity was generally lower $(P<0.05)$ in berries packaged in polystyrene cups after 2 additional days at $16 \mathrm{C}$, regardless of prior storage duration. The $\mathrm{pH}$ ranged from 3.0 to 3.2 among all treatment combinations, and the $\mathrm{pH}$ of 'Climax' berries was significantly higher than that of 'Sharpblue' berries except after overnight and 1 week of storage at 1C. Mean $\mathrm{pH}$ for 'Climax' and 'Sharpblue' was 3.16 and 3.04, respectively, over all storage regimes.

The taste panel preferred the flavor and texture of 'Climax' berries at the initial inspection over the flavor and texture of 'Sharpblue' berries, whereas for berries stored longer than 1 week at $1 \mathrm{C}$, the panel had no preference. After 2 and 3 weeks of storage at $1 \mathrm{C}$, the panel slightly preferred the flavor and texture of 'Sharpblue' berries. Flavor was not affected by cultivar after storage at $16 \mathrm{C}$ for 2 days, regardless of storage duration at $1 \mathrm{C}$. The panel generally favored the texture of 'Sharpblue' berries over that of 'Climax' berries. Type of packaging material generally did not affect the flavor or texture of the blueberries. Although all flavor and texture evaluations were made by the same panelists, it is important to note that cultivars necessarily were rated at different times.

Atmospheres around berries packed in polystyrene cups (with small holes) averaged $21 \% \mathrm{O}_{2}$ and $0.4 \% \mathrm{CO}_{2}$ for both cultivars and did not change during 7,14 , or 21 days of storage at $1 \mathrm{C}$. After 2 additional days at $16 \mathrm{C}$, the $\mathrm{CO}$, concentration increased to $0.6 \%$, but was unaffected by cultivar. Berries packed in fiber-pulp cups were assumed to be at normal atmosphere, since these cups were constructed with eight large vents and had unsealed cellophane covers.

'Sharpblue' berries were softer immediately following harvest than 'Climax' berries, and they remained soft during storage. Previous reports show that soft fruit may not become firmer even when held at near optimum temperatures (Smittle and Miller, 1988). Therefore, we do not recommend 'Sharpblue' berries for distant export markets. Even for domestic sales, 'Sharpblue' berries should be picked as soon as possible after reaching marketable maturity, since blueberries from later harvest dates are ripe, and fruit quality decreases faster during postharvest storage than the quality of fruit from earlier harvests (Ballinger and Kushman, 1970; Ballinger et al., 1978; Galletta et al., 1971; Kushman and Ballinger, 1968; Miller et al., 1988). Shippers can successfully export 'Climax' berries to distant markets, even when transportation time approaches 2 weeks, provided proper temperatures are maintained. Decay in 'Climax' fruit remained relatively low, and vented polystyrene packaging did not affect incidence of decay in 'Climax' berries compared with the fiber-pulp packaging. Hence, the choice of packaging material used for 'Climax' berries depends on market factors. We realize that the 'Sharpblue' cultivar has the earliest harvest date of any commercial blueberry cultivar in
North America, and the incentive for shippers to market 'Sharpblue' berries to distant export markets will likely continue; however, shippers should be aware of the risks of quality decline inherent with these berries.

\section{Literature Cited}

Ballinger, W.E. and L.J. Kushman. 1970. Relationship of stage of ripeness to composition and keeping quality of highbush blueberries. J. Amer. Soc. Hort. Sci. 95:239-242.

Ballinger, W.E., E.P. Maness, and W.F. McClure. 1978. Relationship of stage of ripeness and holding temperature to decay development of blueberries. J. Amer. Soc. Hort. Sci. 103: 130134.

Crocker, T.E. and P.M. Lyrene. 1985. Survey of blueberry acreage in Florida. Proc. Fla. State Hort. Soc. 98:162-164.

Crocker, T.E. and L. Willis. 1989. Survey of southern highbush and rabbiteye blueberries in Florida. Proc. Fla. State Hort. Soc. 102:204-206.

Galletta. G.J.. W.E. Ba1linger. R.J. Monroe, and L.J. Kushman. 1971. Relationships between fruit acidity and soluble solids level of highbush blueberry clones and fruit keeping quality. J. Amer. Soc. Hort. Sci. 96:758-762.

Kushman, L.J. and W.E. Ballinger. 1968. Acid and sugar changes during ripening in 'Wolcott' blueberries. J. Amer. Soc. Hort. Sci. 92:290295.

Lyrene, P.M. and W.B. Sherman. 1988. Cultivation of highbush blueberry in Florida. Proc. Florida State Hort. Soc. 101:269-272.

Miller, W.R., R.E. McDonald, and T.E. Crocker. 1988. Fruit quality of rabbiteye blueberries as influenced by weekly harvest, cultivars, and storage durations. Ho\&Science 23:182-184.

Miller, W.R. and D.A. Smittle. 1987. Storage quality of hand- and machine-harvested rabbiteye blueberries. J. Amer. Soc. Hort. Sci. 112:487490.

Smittle, D.A. and W.R. Miller. 1988. Rabbiteye blueberry storage life and fruit quality in controlled atmospheres and air storage. J. Amer. Soc. Hort. Sci. 113:723-728. 